\title{
Junctional epidermolysis bullosa inversa
}

INSERM

\section{Source}

INSERM. (1999). Orphanet: an online rare disease and orphan drug data base. Junctional epidermolysis bullosa inversa. ORPHA:79405

Junctional epidermolysis bullosa inversa is a rare severe subtype of junctional epidermolysis bullosa (JEB, see this term) characterized by blistering and erosions confined to intertriginous skin sites, the esophagus, and vagina. 